\title{
BMJ Open Teeth Tales: a community-based child oral health promotion trial with migrant families in Australia
}

Lisa Gibbs, ${ }^{1}$ Elizabeth Waters, ${ }^{1}$ Bradley Christian, ${ }^{1}$ Lisa Gold, ${ }^{2}$ Dana Young,,${ }^{1,3}$ Andrea de Silva, ${ }^{4,5}$ Hanny Calache, ${ }^{4}$ Mark Gussy, ${ }^{6}$ Richard Watt, ${ }^{7}$ Elisha Riggs, ${ }^{8}$ Maryanne Tadic, ${ }^{3}$ Martin Hall, ${ }^{9}$ Iqbal Gondal, ${ }^{10}$ Veronika Pradel, ${ }^{3}$ Laurence Moore ${ }^{11}$

To cite: Gibbs L, Waters E, Christian B, et al. Teeth Tales: a community-based child oral health promotion trial with migrant families in Australia BMJ Open 2015;5:e007321. doi:10.1136/bmjopen-2014007321

- Prepublication history and additional material is available. To view please visit the journal (http://dx.doi.org/ 10.1136/bmjopen-2014007321).

Received 1 December 2014 Revised 10 May 2015 Accepted 13 May 2015

CrossMark

For numbered affiliations see end of article.

Correspondence to

Dr Lisa Gibbs;

Igibbs@unimelb.edu.au

\section{ABSTRACT}

Objectives: The Teeth Tales trial aimed to establish a model for child oral health promotion for culturally diverse communities in Australia.

Design: An exploratory trial implementing a communitybased child oral health promotion intervention for Australian families from migrant backgrounds. Mixed method, longitudinal evaluation.

Setting: The intervention was based in Moreland, a culturally diverse locality in Melbourne, Australia.

Participants: Families with 1-4-year-old children, selfidentified as being from Iraqi, Lebanese or Pakistani backgrounds residing in Melbourne. Participants residing close to the intervention site were allocated to intervention.

Intervention: The intervention was conducted over 5 months and comprised community oral health education sessions led by peer educators and follow-up health messages.

Outcome measures: This paper reports on the intervention impacts, process evaluation and descriptive analysis of health, knowledge and behavioural changes 18 months after baseline data collection.

Results: Significant differences in the Debris Index (OR=0.44 (0.22 to 0.88)) and the Modified Gingival Index (OR=0.34 (0.19 to 0.61)) indicated increased tooth brushing and/or improved toothbrushing technique in the intervention group. An increased proportion of intervention parents, compared to those in the comparison group reported that they had been shown how to brush their child's teeth ( $O R=2.65$ (1.49 to 4.69)). Process evaluation results highlighted the problems with recruitment and retention of the study sample (275 complete case families). The child dental screening encouraged involvement in the study, as did linking attendance with other community/cultural activities.

Conclusions: The Teeth Tales intervention was promising in terms of improving oral hygiene and parent knowledge of tooth brushing technique. Adaptations to delivery of the intervention are required to increase uptake and likely impact. A future cluster randomised controlled trial would provide strongest evidence of effectiveness if appropriate to the community, cultural and economic context.

Trial registration number: Australian New Zealand Clinical Trials Registry (ACTRN12611000532909).

\section{Strengths and limitations of this study}

- The community-based participatory approach increased cultural and community engagement and relevance.

- Study eligibility was restricted to three migrant groups due to resource limitations and to provide strict study parameters.

- Study eligibility was not limited to new immigrants, potentially minimising intervention effect but allowing for consideration of ethnicity and migration influences.

- There was non-random allocation to intervention and potential for examiner bias given the difficulty in blinding to intervention and comparison groups when they are locationally based.

- The high loss to follow-up is a limitation in terms of judging the importance of group differences found.

\section{INTRODUCTION}

The population health impact of Early Childhood Caries (ECC) is well recognised ${ }^{12}$ and it remains a public health priority internationally. "Early Childhood Caries is defined as the presence of one or more decayed (noncavitated or cavitated lesions), missing (due to caries) or filled tooth surfaces in any primary tooth in a preschool-age child between birth and 71 months of age". ${ }^{3}$ In the past decade there have been a series of ECC prevention studies using various interventions including parent counselling, ${ }^{4}$ motivational interviewing, ${ }^{5}$ clinical prevention measures ${ }^{6}$ and oral health promotion and education targeted at individuals, families and communities and delivered in various ways and contexts. ${ }^{7-11}$ Evidence of intervention effectiveness in these studies demonstrates the capacity of oral health promotion interventions to encourage short-term change in oral health behaviours. Challenges experienced in some studies highlight the importance of parent/ caregiver involvement, ${ }^{12}$ and sensitivity to 
cultural beliefs and behaviours and community needs and capacity. ${ }^{58}$ The importance of changing tooth brushing behaviour in particular, including use of fluoride toothpaste, was demonstrated by an intervention study in Scotland, which showed that in a sample of 461 children aged 5 years, those who brushed once a day or less had $64 \%$ more caries than those who brushed at least twice a day using a chalk-based toothpaste containing 1000 ppm fluoride. ${ }^{13}$

Inequalities are evident in ECC rates with the socially disadvantaged having a greater burden of disease ${ }^{14-16}$ In Australia, past studies have shown poorer oral health for children from refugee families than the wider population. ${ }^{17-19}$ This study builds on earlier qualitative research conducted in the Moreland and Hume local government areas of Melbourne, Victoria from 2006 to 2009 in response to community concerns for the oral health of children from refugee and migrant backgrounds. ${ }^{20} 21$ An initial systematic review was also conducted which demonstrated the limitations of existing oral health interventions and the need for a culturally appropriate approach. ${ }^{16}$ The development of the community-based intervention described here was informed by the systematic review, a socioecological framework, ${ }^{22}$ the earlier qualitative research ${ }^{17}$ and a small initial pilot. It extends the partnership approach to cogeneration of contemporary evidence with continued and meaningful involvement of researchers, and community, cultural, health and government partners. The exploratory trial is the final phase of the research study extending over 9 years. Full details about the different phases of the study, the logic model and the trial study design and methodology have been previously published in a protocol paper. ${ }^{23}$ The trial, conducted between 2012 and 2014 aimed to establish a model for child oral health promotion for culturally diverse communities in Australia. The intervention had not been finalised nor the study measures sufficiently tested within the cultural and community context of the study to warrant a fully powered trial. Therefore, this study was conducted as an exploratory trial to allow the intervention to be refined, acceptability and uptake tested and evaluation methods including recruitment, retention and measures to be assessed. This has been demonstrated to be a useful research stage, following initial small-scale piloting (modelling), allowing for community participation in the progression towards increasing strength of evidence and in particular to inform a full scale randomised controlled trial. ${ }^{24-28}$

\section{METHODS}

Study design

Teeth Tales was an exploratory trial implementing a community-based child oral health promotion intervention for Australian families from migrant backgrounds, evaluated using longitudinal mixed methods. ${ }^{23}$ It employed a culturally competent, ${ }^{29}{ }^{30}$ community-based participatory research approach ${ }^{31-34}$ and was conducted in partnership with a community health service, three cultural organisations (two are service providers with paid staff, one provides advocacy with volunteers only), State and local government agencies and a nongovernment organisation (Centre for Culture, Ethnicity and Health). All of the investigators and study partners were involved in decision-making at all stages of the study. The participatory approach included: shared staffing and budgeting; colocation of staff across organisations; shared responsibility for training activities, development of study resources, trial implementation and evaluation activities; and shared involvement in dissemination of study findings and ongoing distribution of community resources arising from the study.

\section{Setting and participants}

The target population for Teeth Tales were migrant families with 1-4-year-old children, self-identified as being from Iraqi, Lebanese or Pakistani backgrounds residing in metropolitan Melbourne, Australia. In this study, the term migrant refers to people who have moved to a country to which they are not native, in this case Australia, in order to settle there, especially as permanent residents or future citizens. Migration settlement data identified these groups as having a high representation of young families in the intervention site-the local government area of Moreland. ${ }^{20}{ }^{23}$ They were also identified as being potentially at risk of poor child oral health, as indicated by local dental service data and community information. The 1-4-year-old age group was intended to capture those with primary dentition and still within the ECC age range by the end of the study.

\section{Trial aims and objectives}

The aim of the exploratory trial was to establish a model for feasible, replicable and affordable child oral health promotion for culturally diverse local government areas (LGAs) in Australia. The primary objectives to achieve this were to assess the impact of the intervention on the frequency of child tooth brushing and on parent knowledge of child oral hygiene. Secondary objectives included a process evaluation to determine costs, facilitators and barriers and intervention fidelity and dose. Additional secondary objectives, which were not powered to detect significant differences, included measuring changes in child oral health, oral health behaviours, parent knowledge, parent attitudes (not reported) and dental service access from baseline to follow-up (18 months later) for both intervention and comparison groups to increase knowledge of child oral health profiles in families with a migrant background residing in Melbourne, Australia. ${ }^{23}$

\section{Intervention}

The Teeth Tales intervention aimed to achieve improvements in oral health and healthy behaviours of children and parents of migrant background, and thereby reduce the social gradient evident in child oral health. The intervention consisted of two components: (1) a peer led 
community oral health education programme delivered in culturally appropriate settings by peer educators from the same cultural and language background as the participants to improve parent knowledge, and behaviours in relation to child oral health needs; and (2) a cultural competence organisational review (CORe) conducted to identify and address opportunities to improve access to local community health and government organisations delivering dental and family health and support services. ${ }^{23}$

This paper will focus on the peer educator led community education component of the intervention. Results from the cultural competence organisational review will be reported elsewhere.

The community education sessions for parents were delivered over 2-3 weeks and included two $3 \mathrm{~h}$ sessions of oral health education followed by a site visit to the local community health dental service to be familiarised with the service and other local family services. The education sessions covered the topics of Eat Well, Drink Well, Clean Well and Stay Well adapted from the Dental Health Services Victoria (DHSV) Smiles 4 Miles programme (http://www.dhsv.org.au/smiles4miles/) The sessions also included opportunities to discuss participants' own oral health beliefs, practices and strategies for managing change. Participants were provided with an oral health pack (at no charge) that contained toothbrushes and toothpastes for the whole family and oral health information. They were also given an opportunity to practice brushing their own teeth using plaque disclosing agents to identify areas of plaque stagnation. Follow-up reminders of the key oral health messages were sent by peer educators to community education participants at regular intervals following completion of the programme (one message per month for 4 months). The messages were sent by text, email or post according to the participant's preference. Families allocated to intervention who did not attend community education sessions were sent an oral health pack by mail, unless they had withdrawn from the study.

\section{Recruitment and training of peer educators}

Selection criteria for peer educators was being a member of the same cultural and linguistic background of one of the target groups, being fluent in spoken and written English and their own language, and having an interest in promoting health in their community. The partner cultural advocacy organisation circulated advertisements for peer educators throughout their community networks. Applicants were interviewed and selected by Teeth Tales staff in early 2012. The partner cultural service organisations selected appropriate staff members to be their peer educators. All of the peer educators were then trained by Teeth Tales staff and employed to deliver the intervention and to assist with recruitment and data collection in 2012 from their respective cultural communities. They used purposive and snowball sampling methods, which are known to be effective in recruiting hard to reach populations. ${ }^{35}$ They utilised existing client databases, schools, childcare centres, community and social networks to reach potential participants from across metropolitan Melbourne. They approached families using advertisements, phone calls and in person. Families were invited to attend a child oral health screening session that included recruitment into the study. Detailed contact information was collected to support retention at follow-up, including up to two alternative contacts who could help in reaching families who changed accommodation or phone numbers. Study materials were available in English, Arabic and Urdu. The target sample size was 200 families from each of the Iraqi, Lebanese and Pakistani communities.

\section{Statistical power}

The purpose of an exploratory trial is to assess the feasibility, relevance and costs of the intervention rather than testing for significant change. However, given the target sample size of 600 was relatively large for an exploratory trial, we anticipated sufficient power to detect significant differences in relation to child tooth brushing, assessed by the frequency of tooth brushing and modified gingival index as a proximal indicator. Assuming a sample size of 600 families (300 per arm) considered feasible for recruitment, and allowing for a 20\% drop out, a two tailed $\alpha$ of 0.05 and no clustering effects, there was $95 \%$ power to detect a $25 \%$ change in tooth brushing frequency. This is consistent with the level of change seen in other oral health promotion intervention studies. ${ }^{86}$ We also anticipated that there would be power to detect a difference of reasonable magnitude in parent knowledge of child oral hygiene needs, with similar power calculations.

\section{Allocation to intervention-oral health education}

Following recruitment, community participants were allocated to the intervention arm if they resided within Moreland or any adjacent LGAs, to ensure they had access to the intervention and to services introduced as part of the programme. Families recruited from outside these areas were treated as the comparison group.

\section{Data collection}

Baseline data collection for Teeth Tales was conducted in community settings between March and September 2012. Follow-up data collection was conducted from September to December 2013.

Dental practitioners conducted the dental screening of all child participants, with the child lying down in the lap-to-lap position (the child sitting on his/her parents lap, facing the parent and then allowed to lie back with their head resting on the dental practitioner's lap) and using a disposable mouth mirror, head lamp and standard infection control equipment. Dental caries was assessed using a modified version (no drying of teeth) of the International Caries Detection and Assessment System-ICDAS II. $^{37}$ Children with identified caries were referred to the local public dental service for treatment as required. Measures of debris on the child's 
teeth (Debris Index) and gingival inflammation (Modified Gingival Index) were also included as proxy indicators of tooth brushing. ${ }^{38}$ Dental examiners were trained and calibrated in ICDAS II using the ICDAS Foundation e-Learning training programme (https:// www.icdas.org/elearning-programmes). Inter-rater and intra-rater reliability scores were computed following dental examiner scoring of clinical photographs of various stages of caries lesions. Calibration in use of the Modified Gingival Index followed a similar pattern to that of ICDAS II, using a training package developed by Teeth Tales clinical and research personnel in the absence of an industry training resource.

Parents were asked to complete a structured selfadministered questionnaire at baseline and follow-up, developed to collect information on child and parent demographics, oral hygiene behaviour, dental visiting behaviour, self-reported health measures, child dietary practices and parent oral health knowledge (see online supplementary file for copy of questionnaire).

Process evaluation data was recorded by cultural partners to track recruitment activity, participant attendance at recruitment and follow-up sessions and intervention dose. Teeth Tales staff and peer educators recorded all resources (time, space and materials) required to provide the intervention. Three focus group discussions with all available peer educators and administrators, one discussion for each of the cultural partners involving 2-3 participants, were also conducted by the researchers after follow-up to explore barriers and facilitators to trial implementation. The discussions were audio recorded and transcribed verbatim. QSR NVivo 10 was used as a data management tool.

\section{ANALYSIS}

\section{Primary outcome variables}

The measure of child tooth cleaning frequency was the question 'How often is the child's teeth/mouth cleaned?'. This variable was dichotomised into those that brush less than twice/day and those that brush at least twice per day, as brushing twice a day with a fluoride toothpaste has been shown to be more effective in reducing caries. ${ }^{13}{ }^{39-41}$ The five oral health knowledge questions (When should the child's teeth be cleaned?, Has anyone ever shown you how to clean this child's teeth and gums?, Does fluoride in water prevent caries?, If my child has a dental problem I know what to do and Does a bottle in bed cause tooth decay?) were also dichotomised for this analysis. For the proxy measures of child tooth cleaning frequency and effectivenessDebris Index and the Modified Gingival Index, binary variables were generated for the presence or absence of debris on the teeth and gingival inflammation.

\section{Statistical analysis of the primary outcomes}

Approximately $47 \%$ of families were lost to follow-up. This level of missing data cannot be assumed to be missing at random and so use of techniques to impute the missing data would be innappropriate. Hence, only a complete case analysis was conducted, using logistic regression to compare change in the primary outcome variables from baseline by study group. An intentionto-treat analysis of the results was conducted based on the initial treatment assignment and not on the treatment eventually received. Analysis was conducted first adjusting only for baseline value and family cluster and second adjusting also for the following confounding variables: ethnicity, length of time in Australia, socioeconomic status (parent education and healthcare card status) and demographics (child age, child sex, parent age and parent sex) in recognition of the influence of these factors on child oral health in our analysis of the baseline data (not yet published). Data were analysed using STATA V.12.1.

\section{Process and cost evaluation}

Data from project documentation was used to generate descriptive statistics for recruitment activity and dose and reach of the intervention. Economic data on resources used (primarily staff time as well as travel, venue and refreshment costs) were valued in 2012 Australian dollars using market prices and standard unit cost data sources. The data from the follow-up focus group discussions with cultural partners was coded and categorised by the two researchers who led the focus group discussions. An inductive thematic analysis was then conducted jointly to explore intervention barriers and facilitators to trial implementation. Researcher observation of community education sessions also informed an understanding of barriers and facilitators to implementation.

\section{RESULTS}

\section{Response rates}

Recruitment resulted in 521 families (692 children) participating in baseline data collection and 53\% (275 families, 365 children) returning for follow-up data collection (figure 1: Flow diagram of recruitment and data collection).

\section{Sample characteristics}

There was no significant difference between intervention and comparison groups in rates of attrition (table 1). Attrition was also similar across parent age, sex and socioeconomic status. However, families from the Lebanese community, parents born in Australia and parents with English as their preferred language tended to be more likely to drop out.

At baseline, demographic characteristics of the sample of complete cases (ie, those who participated in baseline and follow-up) were similar between the intervention and comparison groups, except in relation to the age of the child (table 2). Overall, 52\% of participating children and $81 \%$ of participating parents were female. The distribution of children by ethnicity was $39 \%$ Iraqi, $17 \%$ 
Figure 1 Flow of participants through the trial.

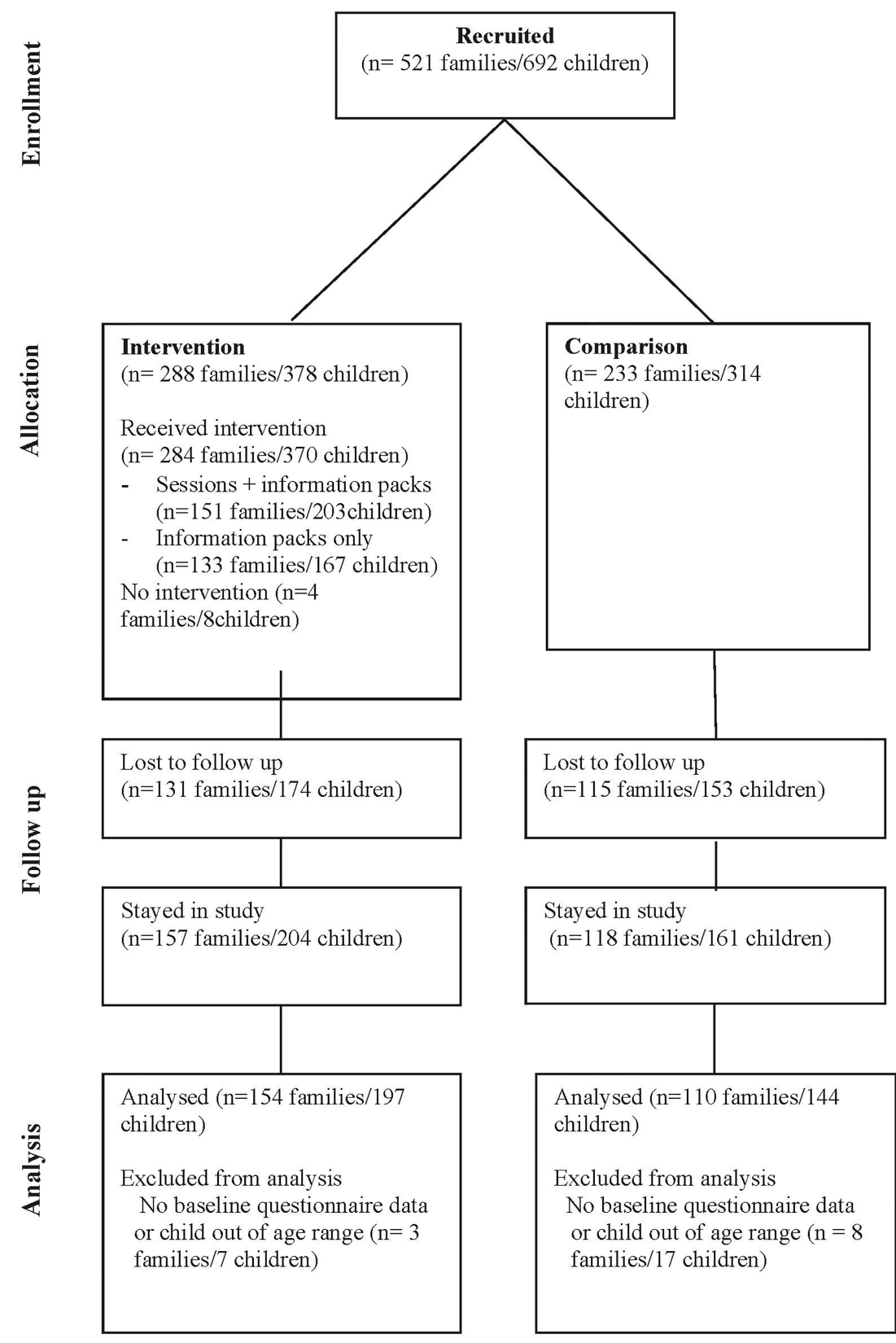

Lebanese and $44 \%$ Pakistani. The majority of parent respondents (79\%) reported that English was not their preferred language.

\section{Primary outcomes-intervention effect}

Significant differences in the Debris Index and the Modified Gingival Index indicated increased tooth brushing and/or improved technique in the intervention group. Children in the intervention group were $56 \%$ less likely to have debris present on teeth compared to children in the comparison group ( $\mathrm{OR}=0.44$ ( 0.22 to $0.88)$ ), and $66 \%$ less likely to show signs of gingival inflammation $(\mathrm{OR}=0.34$ (0.19 to 0.61$)$; table 3$)$. The results from the Modified Gingival Index alone should be treated with caution because of moderate inter-rater reliability, with weighted $\kappa$ scores ranging from 0.49 to 0.54 . However, in support of this finding, parents in the intervention group were 2.65 times more likely than parents in the comparison group to report that they had been shown how to clean their child's teeth $(\mathrm{OR}=2.65$ (1.49 to 4.69$)$ ).

There was a $19 \%$ increase from baseline to follow-up in the proportion of children whose parents reported their teeth were brushed at least twice per day in the intervention group, compared to an $11 \%$ increase in the comparison group; this difference between groups was not statistically significant (table 3 ).

There were no statistically significant differences found between intervention and comparison groups at follow-up in relation to other aspects of parent oral health knowledge (table 3).

To further explore the impact of intervention dose on results, we split the complete case intervention group into those that attended one or more peer educator sessions 
Table 1 Comparison of demographic characteristics of families that stayed-in with those that were lost at follow-up

\begin{tabular}{|c|c|c|c|}
\hline Demographics characteristics & Stayed in to follow-up & Dropped out & p Value ${ }^{\star}$ \\
\hline Study groups & $\mathrm{N}=264$ & $\mathrm{~N}=229$ & 0.302 \\
\hline Intervention & $154(58 \%)$ & $123(54 \%)$ & \\
\hline Comparison & $110(42 \%)$ & $106(46 \%)$ & \\
\hline Parent sex & $\mathrm{N}=264$ & $\mathrm{~N}=229$ & 0.348 \\
\hline Male & $50(19 \%)$ & $36(16 \%)$ & \\
\hline Female & $214(81 \%)$ & $193(84 \%)$ & \\
\hline Parent age in years & $N=247$ & $\mathrm{~N}=213$ & 0.541 \\
\hline Mean (SD) & 33.74 years $(6.01)$ & 33.89 years $(6.59)$ & \\
\hline $18-25$ years & $14(6 \%)$ & $18(8 \%)$ & \\
\hline $26-35$ years & $155(63 \%)$ & $129(61 \%)$ & \\
\hline $36-45$ years & $70(28 \%)$ & 56 (26\%) & \\
\hline$>46$ years & $8(3 \%)$ & $10(5 \%)$ & \\
\hline Cultural group & $\mathrm{N}=264$ & $\mathrm{~N}=229$ & $<0.001$ \\
\hline Iraqi & $102(38 \%)$ & 77 (33\%) & \\
\hline Lebanese & $47(18 \%)$ & $102(45 \%)$ & \\
\hline Pakistani & $115(44 \%)$ & $50(22 \%)$ & \\
\hline Preferred language & $\mathrm{N}=264$ & $\mathrm{~N}=229$ & $<0.001$ \\
\hline English & $59(22 \%)$ & $93(41 \%)$ & \\
\hline Non-English & $205(78 \%)$ & $136(59 \%)$ & \\
\hline Length of stay in Australia & $\mathrm{N}=241$ & $\mathrm{~N}=214$ & $<0.001$ \\
\hline Median (IQR) & 7 years $(4-14)$ & 12 years $(6-28)$ & \\
\hline $0-5$ years & $65(27 \%)$ & $32(15 \%)$ & \\
\hline $6-10$ years & $77(31 \%)$ & $50(23 \%)$ & \\
\hline $11-15$ years & $45(19 \%)$ & $44(21 \%)$ & \\
\hline$>15$ years & $28(12 \%)$ & $30(14 \%)$ & \\
\hline Born in Australia & $26(11 \%)$ & $58(27 \%)$ & \\
\hline Parent's education level & $\mathrm{N}=259$ & $\mathrm{~N}=223$ & 0.396 \\
\hline Primary school or less & $43(17 \%)$ & $39(17 \%)$ & \\
\hline Secondary school & $85(33 \%)$ & $85(38 \%)$ & \\
\hline Trade & $27(10 \%)$ & 26 (12\%) & \\
\hline University & $104(40 \%)$ & $73(33 \%)$ & \\
\hline Healthcare card status & $\mathrm{N}=258$ & $\mathrm{~N}=227$ & 0.121 \\
\hline No & $80(31 \%)$ & $56(25 \%)$ & \\
\hline Yes & $178(69 \%)$ & $171(75 \%)$ & \\
\hline
\end{tabular}

$(\mathrm{n}=151)$ and those that only received the oral health pack $(\mathrm{n}=133)$. This post hoc analysis suggests that intervention effects were indeed concentrated in those who had received both community education and the oral health packs (see online supplementary file-table a).

Secondary outcomes-changes in oral health status, behaviours, knowledge and use of dental services

A comparison of baseline and follow-up secondary outcomes for child oral health status, child and parent oral health behaviours and parent knowledge was conducted (see online supplementary file-table b). They show a common pattern of results with no differences between intervention and comparison groups over time in increase in child caries experience, dental visits or addition of sugar to children's drinks. Parents in both groups also reported increased confidence in knowing how to take care of their child's oral health. There was however a different pattern between the type of dentist being accessed for child dental care with more children from the intervention group reported to have accessed a public dentist and more from the comparison group reported to have accessed a private dentist.

\section{Process evaluation findings}

The review of recruitment challenges, intervention dose, intervention fidelity, retention, unanticipated outcomes and costs, conducted for the process evaluation, is reported below, incorporating details about associated facilitators and barriers to successful intervention implementation where relevant.

\section{Recruitment challenges}

The follow-up focus group discussions with the cultural partner organisations revealed that all had found it very difficult to recruit families to the study and to engage the families allocated to intervention in the community education sessions.

Many of the families (32\%) who indicated interest in the study and agreed to come to the next recruitment 
Table 2 Comparison of child and parent demographics and outcome variables of interest between intervention and comparison arms for the complete case sample at baseline

\begin{tabular}{|c|c|c|}
\hline Variables & Intervention & Comparison \\
\hline $\begin{array}{l}\text { Number of children } \\
(\mathrm{N}=341)\end{array}$ & $\mathrm{N}=197$ & $N=144$ \\
\hline Child age & $N=197$ & $\mathrm{~N}=144$ \\
\hline 1-year-olds & $45(23 \%)$ & 34 (24\%) \\
\hline 2-year-olds & $53(27 \%)$ & $33(23 \%)$ \\
\hline 3-year-olds & $42(21 \%)$ & 52 (36\%) \\
\hline 4-year-olds & 57 (29\%) & 25 (17\%) \\
\hline Child sex & $N=197$ & $\mathrm{~N}=144$ \\
\hline Female & $100(51 \%)$ & $76(53 \%)$ \\
\hline Male & $97(49 \%)$ & 68 (47\%) \\
\hline Parent age & $N=183$ & $\mathrm{~N}=136$ \\
\hline Mean (SD) & $\begin{array}{l}33.24 \text { years } \\
(5.77)\end{array}$ & $\begin{array}{l}33.50 \text { years } \\
(5.99)\end{array}$ \\
\hline $18-25$ & $13(7 \%)$ & $8(6 \%)$ \\
\hline $26-35$ & $117(64 \%)$ & $92(68 \%)$ \\
\hline $36-45$ & $49(27 \%)$ & $30(22 \%)$ \\
\hline$>46$ & $4(2 \%)$ & $5(4 \%)$ \\
\hline Parent sex & $\mathrm{N}=197$ & $N=144$ \\
\hline Female & $164(83 \%)$ & $112(78 \%)$ \\
\hline Male & $33(17 \%)$ & $32(22 \%)$ \\
\hline Cultural group & $N=197$ & $N=144$ \\
\hline Iraqi & 75 (38\%) & $58(40 \%)$ \\
\hline Lebanese & $32(16 \%)$ & $26(18 \%)$ \\
\hline Pakistani & 90 (46\%) & 60 (42\%) \\
\hline Preferred language & $\mathrm{N}=197$ & $\mathrm{~N}=144$ \\
\hline English & 37 (19\%) & 35 (24\%) \\
\hline Non-English & $160(81 \%)$ & 109 (76\%) \\
\hline Length of stay & $\mathrm{N}=180$ & $\mathrm{~N}=131$ \\
\hline Median (IQR) & 7 years (4-12) & 8 years $(5-14)$ \\
\hline $0-5$ years & $49(27 \%)$ & $29(22 \%)$ \\
\hline $6-10$ years & $43(24 \%)$ & 44 (34\%) \\
\hline $11-15$ years & 32 (18\%) & $26(20 \%)$ \\
\hline$>15$ years & $16(9 \%)$ & $17(13 \%)$ \\
\hline Born in Australia & $20(11 \%)$ & $14(11 \%)$ \\
\hline $\begin{array}{l}\text { Parent's education } \\
\text { level }\end{array}$ & $\mathrm{N}=193$ & $N=142$ \\
\hline Primary or less & $33(17 \%)$ & $23(16 \%)$ \\
\hline Secondary & $62(32 \%)$ & 45 (32\%) \\
\hline Trade & $21(11 \%)$ & $16(11 \%)$ \\
\hline University & 77 (40\%) & $58(41 \%)$ \\
\hline Healthcare card status & $\mathrm{N}=193$ & $\mathrm{~N}=141$ \\
\hline No & $56(29 \%)$ & $52(37 \%)$ \\
\hline Yes & $137(71 \%)$ & 89 (63\%) \\
\hline
\end{tabular}

and oral health screening session did not actually attend, despite reminder calls and text messages made on the day before or morning of the session. Peer educators reported cultural influences in this pattern of responses, with many agreeing to attend in order to be polite-'they prefer not to say no up front, in order not to be rude.'

Peer educators employed many strategies to recruit families, including local door knocking, visits to schools and kindergartens and community events, and media promotions. One of the factors that made recruitment more difficult was that recruitment for each cultural partner was restricted to a particular ethnicity. This restriction was included to allow for comparison of intervention impact by ethnic group and to prevent overlap in the recruitment activities of the agencies. However, this approach was incompatible with the way these agencies operate and the realities of community engagement, for example when recruiting in a school or kindergarten there was likely to be a mix of nationalities present.

...next time you give us a geographical location rather than target group so if we are targeting a school we can't say to Arabic parents you're Lebanese you can't come to the program because you're Lebanese. Or you can't come because your Iraqi, it's not really nice, because we work with the diversity of the community.

One of the cultural partners reported that the Lebanese families were well established in Australia and so were less open to new information-"we don't need [you] to tell us what is the issues". In contrast, the parents from the Iraqi and Pakistani families tended to have resided in Australia for less than 15 years. Others reported that the busyness of people's lives prevented them from prioritising the recruitment and community education sessions.

Reported facilitators to engagement included making personal contact with families, parents' interest in a free dental screening for their child, and peer educators' knowledge of cultural subtleties:

...sometimes we have to go to the stranger's house, we always look ... because in our culture we keep our shoes outside the house, so we are always looking where are the shoes at the house? So those houses we can go knock on the door.

One of the agencies also timed and co-located the recruitment sessions to link with other family services that they deliver. This was found to encourage people to attend and introduced new families to their other services as well.

\section{Intervention fidelity}

Observations of community education sessions by the research team and findings from the follow-up focus group discussions with the cultural partners confirmed that the training manual provided for the delivery of the community education sessions was closely followed. The manual provided a simple script for the peer educators to follow for each session with accompanying visual resources and practical exercises to accommodate the potential low literacy of participating parents. The manual was universally described in the follow-up focus group discussions with the partner cultural organisations as a useful tool for communication of the key oral health messages of Eat Well, Drink Well, Clean Well and Stay Well.

Peer educators also reported in the focus group discussions that the participants in the community 
Table 3 Comparing baseline and follow-up child level estimates for intervention impacts on the primary outcomes

\begin{tabular}{|c|c|c|c|c|c|c|c|c|c|c|}
\hline \multirow[b]{2}{*}{$\begin{array}{l}\text { Primary } \\
\text { outcomes }\end{array}$} & \multicolumn{2}{|l|}{ Baseline } & \multicolumn{2}{|l|}{ Follow-up } & \multicolumn{3}{|c|}{ Partially adjusted model* } & \multicolumn{3}{|c|}{ Fully adjusted model† } \\
\hline & $\begin{array}{l}\text { Estimate } \\
(\%)\end{array}$ & $95 \% \mathrm{Cl}$ & $\begin{array}{l}\text { Estimate } \\
(\%)\end{array}$ & $95 \% \mathrm{Cl}$ & OR & $95 \% \mathrm{Cl}$ & $\begin{array}{l}p \\
\text { Value }\end{array}$ & OR & $95 \% \mathrm{Cl}$ & $\begin{array}{l}\mathbf{p} \\
\text { Value }\end{array}$ \\
\hline \multicolumn{11}{|c|}{ Tooth cleaning at least 2/day } \\
\hline Comparison & 26 & $19 \%$ to $34 \%$ & 37 & $29 \%$ to $45 \%$ & 1.00 & & & 1.00 & & \\
\hline Intervention & 23 & $17 \%$ to $30 \%$ & 42 & $34 \%$ to $49 \%$ & 1.29 & 0.74 to 2.23 & 0.361 & 1.41 & 0.77 to 2.58 & 0.259 \\
\hline \multicolumn{11}{|c|}{ Clean child's teeth when first baby teeth appear } \\
\hline Comparison & 37 & $29 \%$ to $46 \%$ & 28 & $21 \%$ to $37 \%$ & 1.00 & & & 1.00 & & \\
\hline Intervention & 37 & $30 \%$ to $44 \%$ & 38 & $31 \%$ to $48 \%$ & 1.64 & 0.86 to 3.15 & 0.131 & 1.46 & 0.71 to 3.02 & 0.300 \\
\hline \multicolumn{11}{|c|}{ Has anyone shown you how to clean child's teeth/mouth? Yes } \\
\hline Comparison & 29 & $21 \%$ to $37 \%$ & 43 & $35 \%$ to $51 \%$ & 1.00 & & & 1.00 & & \\
\hline Intervention & 39 & $33 \%$ to $47 \%$ & 68 & $60 \%$ to $74 \%$ & 2.67 & 1.54 to 4.61 & $<0.001$ & 2.65 & 1.49 to 4.69 & 0.001 \\
\hline \multicolumn{11}{|c|}{ Does fluoride in water prevent caries? Yes } \\
\hline Comparison & 45 & $36 \%$ to $53 \%$ & 46 & $38 \%$ to $55 \%$ & 1.00 & & & 1.00 & & \\
\hline Intervention & 53 & $45 \%$ to $60 \%$ & 60 & $53 \%$ to $67 \%$ & 1.69 & 0.95 to 3.00 & 0.072 & 1.57 & 0.86 to 2.86 & 0.140 \\
\hline \multicolumn{11}{|c|}{ If child has a dental problem I know what to do. Yes } \\
\hline Comparison & 47 & $39 \%$ to $56 \%$ & 75 & $67 \%$ to $81 \%$ & 1.00 & & & 1.00 & & \\
\hline Intervention & 46 & $39 \%$ to $54 \%$ & 70 & $62 \%$ to $76 \%$ & 0.77 & 0.40 to 1.51 & 0.460 & 0.79 & 0.39 to 1.62 & 0.534 \\
\hline \multicolumn{11}{|c|}{ Does a bottle in bed cause caries? Yes } \\
\hline Comparison & 63 & $54 \%$ to $71 \%$ & 71 & $62 \%$ to $78 \%$ & 1.00 & & & 1.00 & & \\
\hline Intervention & 65 & $58 \%$ to $72 \%$ & 72 & $65 \%$ to $78 \%$ & 1.05 & 0.56 to 1.96 & 0.879 & 1.07 & 0.54 to 2.13 & 0.825 \\
\hline \multicolumn{11}{|c|}{ Tooth debris present } \\
\hline Comparison & 52 & $44 \%$ to $61 \%$ & 86 & $79 \%$ to $91 \%$ & 1.00 & & & 1.00 & & \\
\hline Intervention & 60 & $52 \%$ to $67 \%$ & 73 & $66 \%$ to $79 \%$ & 0.42 & 0.21 to 0.80 & 0.010 & 0.44 & 0.22 to 0.88 & 0.021 \\
\hline \multicolumn{11}{|c|}{ Presence of gingival inflammation $\ddagger$} \\
\hline Comparison & NA & NA & 74 & $66 \%$ to $81 \%$ & 1.00 & & & 1.00 & & \\
\hline Intervention & NA & NA & 46 & $38 \%$ to $53 \%$ & 0.29 & 0.17 to 0.51 & $<0.001$ & 0.34 & 0.19 to 0.61 & $<0.001$ \\
\hline
\end{tabular}

${ }^{*}$ Partially adjusted ORs, adjusted for family clusters and the corresponding variable at baseline.

†Adjusted ORs, adjusted for family clusters, baseline outcome estimate and other variables, in recognition of the influence of these factors on child oral health through findings from the analysis of the baseline data such as-child age, child sex, parent age, parent sex, ethnic background, parent's length of stay in Australia, parent's preferred language, parent's education and healthcare card status.

$\ddagger$ Measured only at follow-up.

na, not applicable.

education sessions had found the information useful and relevant, often to their surprise and that it had inspired them to make changes in their homes:

Well, after session number one, we'd ask them to, by next week, I'm going to ask you what have you changed and a lot would say, oh you know what, I took out all of the caffeine, the coke, coca cola bottles out of the fridge, I haven't bought anything of that sort for a week, so that was the sort of thing we got from one session, to another.

They suggested that people with higher levels of education seemed more willing to attend and that while participants were keen to implement changes, convincing husbands and grandparents to support the changes was sometimes a challenge.

\section{Intervention dose}

Records kept by peer educators show that across all cultural groups, of those allocated to the intervention group, $25 \%$ received all modules of the community education intervention consisting of: two $3 \mathrm{~h}$ group sessions with the peer educator; one session visiting the dental service and receiving information and viewing demonstrations regarding dental visits and other family relevant health and community services; a family oral health pack consisting of toothbrushes and toothpaste and information about the key oral health messages in appropriate languages; and follow-up reminder messages (see online supplementary file-figure a).

Once a family did attend a session it was very rare for them not to attend the second community education session. This supports the feedback from peer educators that it was very difficult to engage parents in the community education sessions initially, in some cases taking up to nine attempts to contact parents, but once they did attend they found the sessions very interesting and useful and were happy to come back to a second session. However, there was a drop off once again for the site visit to the dental clinic at the community health centre, perhaps because of inconvenience or a perception by parents that it was less relevant to them.

\section{Retention}

There was a high loss to follow-up in the study (47\%) with all of the peer educators reporting difficulties in encouraging families to participate in follow-up data collection sessions. Multiple attempts were made to re-engage families (see online supplementary file- 
figure b). Peer educators spoke of families having other competing commitments. Peer educators also noted that many families had moved, sometimes multiple times, and it was not possible to reach them despite efforts at recruitment to record alternative contacts:

...also because they're new arrivals, often people will change their address from there and there, so they can't continue with us.

We need to make sure the forms are correct because for some they put the same number in different contacts (additional contacts) as well, same home number.

\section{Additional outcomes}

Cultural partners reported that their involvement in the research experience had been positive. While the recruitment difficulties were unexpected, and the research documentation and the questionnaire were considered too burdensome for families, they said they had found it rewarding as a community organisation. This was supported by the continued provision of the community education sessions by one of the partner organisations, the proposal for a new joint research study by another and the engagement of peer educators from the third partner in a new community project being led by the community health service. The community health service offers the Teeth Tales Community Oral Health Education Manual for use by other interested organisations and continues to provide child dental screening in community settings, with priority given to disadvantaged families who may experience barriers to accessing dental services.

The Pakistani peer educators who were not part of an established ethno-specific agency described the difficulty of identifying eligible families without an existing client base and networks. However, by going door to door in an area with a high proportion of Pakistani families according to census data, they were able to find families who lived close to each other and the process of providing them with transport and bringing them to recruitment and then to community education sessions together helped to create ongoing social connections between previously isolated mothers.
Another unanticipated experience of the trial was the number of fathers from all cultural groups, approximately $16 \%$ of all parents/caregivers who attended the recruitment and dental screening sessions and from the Iraqi families in particular who attended community education sessions, suggesting the intervention may be a positive way to engage fathers in children's health promotion:

...compared to any other program that we've ever ran, usually we get mums and the kids, mums and the kids, and with this particular one we had the dads and the kids. So that shows the dental care is in the hands of the dads. And that is a very big learning for me, like if I would want to have a dad I would have a dental education as a way to get them involved... because we often look for ways how to engage men.

\section{Costs}

Costs of delivering the intervention averaged $\$ 709$ per family in the intervention group. Costs largely related to the time spent by peer educators in delivering the community sessions and in general activities associated with attempts to get community members to participate and remain in the intervention (table 4 ).

\section{DISCUSSION}

This exploratory trial provided an opportunity to assess the feasibility, relevance and costs of the Teeth Tales intervention as a model for child oral health promotion for culturally diverse LGAs in Australia. Given the relatively large planned sample size, it was also considered possible to test the impact of the intervention on key intervention outcomes-frequency of tooth brushing and parent knowledge of child oral hygiene needs. However, recruitment levels $(\mathrm{n}=521)$ and retention rates $(53 \%)$ did not reach the original targets, as was experienced in a similar child oral health study with families from a migrant background, reporting a 59\% retention rate. ${ }^{4}$ This greatly reduced the power of the current study to detect intervention effects. Families more likely to drop out were those with parents born in Australia, of Lebanese background and English speaking. These

Table 4 Costs of delivery the peer education intervention, per family (\$ 2012)

\begin{tabular}{llc}
\hline Cost category & Cost items & Equivalent cost per family \\
\hline General administration (including recruitment and retention) & & $\$ 246.02$ \\
& Peer educator time & $\$ 221.73$ \\
& Other staff time & $\$ 13.27$ \\
Peer educator training & Travel and communication costs & $\$ 11.02$ \\
Community education sessions & (All components) & $\$ 40.61$ \\
& & $\$ 422.43$ \\
Total & Peer educator time & $\$ 254.99$ \\
& Other staff time & $\$ 46.62$ \\
\hline
\end{tabular}


families are more established in Australia and thus would be expected to have better access to relevant information and services, however earlier Teeth Tales research findings have shown that they are not necessarily at reduced risk of child oral health problems. The retention of families with a non-English speaking background reflects the critical involvement of the cultural partners as the 'face' of the study. However, any apparent patterns in terms of retention and drop out are inconclusive as it is also possible that drop out in each group may have been differential in terms of intervention engagement and service use, raising the potential for bias in the results. Another large 5-year study of oral health disparities in children, with a clinical intervention and no cultural partners, found that children of immigrant parents were more likely to withdraw from the study. ${ }^{42}$ This was not associated with language preference or recency of immigration. Most families who withdrew did not provide a reason or simply lost contact.

The collective indicators of tooth brushing suggest that the Teeth Tales peer led community education programme is a promising means of improving child oral hygiene. The strong trend showing increases in parent report of child tooth brushing frequency did not reach significance, perhaps because the reduced sample size did not have sufficient statistical power to detect difference or because dichotomisation of responses reduced the sensitivity of the measure. However, the likelihood of an intervention effect is supported by the positive impacts on oral hygiene and gum health, and by significantly more parents from the intervention group reporting they had been shown how to clean their child's teeth. This suggests that improved quality of tooth brushing technique was the main positive outcome of the intervention. The provision of free family packs of toothbrushes and toothpaste as part of the intervention may also have been a factor encouraging increased frequency of tooth brushing, ${ }^{13}$ but given follow-up data collection was conducted well after the toothbrushes and toothpaste were likely to have been used and discarded they are unlikely to have been the only influence on tooth brushing behaviour.

Improvements from baseline to follow-up in parent knowledge for both intervention and comparison groups suggest that the dental screening experience and/or the increasing age of the child, had a role in influencing parent knowledge. Increased knowledge of the role of fluoride in water in the intervention group, although not reaching significance, suggested that the community education programme has the potential to support increased parent knowledge on this topic. Service access findings showed that more children in the intervention group accessed the public dental service, rather than a private dental clinic. As a secondary outcome of an exploratory study this was not tested for significance but may indicate an impact of the site visit to the local public dental service as part of the intervention.
The lack of any intervention effect from the oral health packs alone demonstrates the inadequacy of providing only information and toothbrushes/toothpaste in influencing behaviour, ${ }^{43}$ although it has to be acknowledged that those who received only the oral health pack were less likely to be motivated to change given that they had effectively opted out of the community education sessions.

The involvement of the cultural partners was clearly a critical factor in recruiting 521 families with a migrant background. The importance of a shared language and culture in the sharing of oral health knowledge has been reported in similar studies, ${ }^{4}$ as has involvement of other community-based partners such as Maternal and Child Health Nurses. $^{7}$ The recruitment difficulties reported by all of the cultural partners in the current study is not necessarily unique to families with a migrant background, as similar recruitment difficulties were reported by an earlier oral health study based in rural Australia with low cultural diversity. ${ }^{7}$ Regardless, the difficulties experienced by the partners in encouraging families to attend the intervention indicated that the model for intervention delivery needs further development and alignment with existing community and social groups, events and services to encourage uptake. In doing so it needs to address the needs of both newly arrived families and those who are more established in Australia and may feel they are less in need of health promotion information. The inclusion of community-based dental screenings even in the absence of an evaluation component is advisable both to encourage involvement and as a means of increasing parent awareness of child oral health status, introducing parents to local dental practitioners and increasing knowledge about child oral hygiene needs. The intervention may also provide a mechanism for engaging fathers in services and programmes being offered by cultural organisations. Widening the intervention to include grandparents can also be a useful way of overcoming differences in opinion about what is good for the child. ${ }^{10}$ Making the programme available to all interested parties may reduce the costs associated with recruitment in the current study but care would need to be taken to ensure that the benefits of having open discussions about beliefs and practices with people from similar backgrounds is not undermined.

Study limitations include high loss to follow-up, restriction of eligibility to three migrant groups, non-random allocation to intervention and potential for examiner bias given the difficulty in blinding to intervention and comparison when they are locationally based. Many of these limitations were necessary to balance study needs with resource limitations, research parameters and a real-world setting. A multisite, multiethnicity cluster randomised controlled trial, with a measure of sustainability of intervention effect over time, would provide the strongest evidence of effectiveness of the Teeth Tales intervention. While RCTs would provide the strongest 
evidence; a clustered quasi-experimental design would likely be a more feasible future intervention design for public health initiatives of this type. Accommodation of cultural, community and service delivery realities are paramount in considerations of research study design, as is appropriate investment of resources. In this study, the resources required to provide the intervention summed to just over $\$ 700$ per family, so all potential outcomes need to be considered in light of how else that investment could be used. A cost-effectiveness analysis would also assist to determine if the short-term expense of the intervention is justified by long-term benefit.

\section{CONCLUSION}

Alignment with cultural competence principles and use of a community participatory approach enhanced the level of community engagement and cultural relevance of the Teeth Tales study. However, cultural partners still experienced difficulties in recruiting families to the study and the intervention. The Teeth Tales intervention was promising in terms of increasing child oral hygiene, showing parents how to brush their children's teeth and potentially in introducing families to local public dental services. However, these potential outcomes need to be judged against the investment of community resources required. Adaptations to delivery of the model are required to increase uptake and likely impact. Reduction in the parent questionnaire would also minimise the research burden.

\section{Author affiliations}

${ }^{1}$ Jack Brockhoff Child Health and Wellbeing Program, Melbourne School of Population and Global Health, University of Melbourne, Carlton, Victoria, Australia

${ }^{2}$ Deakin Health Economics, Deakin University, Burwood, Victoria, Australia

${ }^{3}$ Merri Community Health Services, Brunswick, Victoria, Australila

${ }^{4}$ Dental Health Services Victoria, Carlton, Victoria, Australia

${ }^{5}$ Melbourne Dental Health School, University of Melbourne, Carlton, Victoria, Australia

${ }^{6}$ Department of Dentistry and Oral Health, La Trobe Rural Health School, La Trobe University, Bendigo, Victoria, Australia

${ }^{7}$ Epidemiology and Public Health, University College London, London, UK

${ }^{8}$ Healthy Mothers Healthy Families Research Group, Murdoch Childrens Research Institute, Carlton, Victoria, Australia

${ }^{9}$ North Richmond Community Health Limited, Richmond, Victoria, Australia

${ }^{10}$ Internet Commerce Security Lab, Federation University Australia and Pakistan Australia Association Melbourne, Caulfield, Victoria, Australia ${ }^{11} \mathrm{MRC} / \mathrm{CSO}$ Social and Public Health Sciences Unit, University of Glasgow, Glasgow, UK

Acknowledgements The authors would like to dedicate this paper to the memory of Coralie Mathews, a much loved member of the Teeth Tales team and the heart and soul of the Teeth Tales project. The authors also wish to thank the research participants who were willing to participate in the trial, the peer educators who have shown considerable skill and commitment to the trial, and the many cultural, community and government organisations who have supported its development and implementation. In particular, the authors wish to acknowledge our colleagues and representatives from partner organisations on the Teeth Tales study who chose not to be authors on this paper but have contributed conceptually and in practical terms to the trialArabic Welfare, Victorian Arabic Social Services, Pakistani Australia Association Melbourne, Merri Community Health Services, North Richmond
Community Health, Centre for Culture, Ethnicity and Health, Moreland City Council and Yarra City Council. The authors also wish to thank the Victorian Department of Education and Early Childhood Development for their support of this study.

Contributors LG was principal investigator of the study and drafted the paper. All of the coauthors contributed to the study design and to the completion of the manuscript. EW contributed to the cross-disciplinary approach and evidence base contributions. BC contributed to the data collection, data management and conducted the quantitative data analyses. LG conducted the economic analysis. DY contributed to intervention and data collection and qualitative data analysis. AdS contributed to data analysis decision-making and reporting of findings. HC contributed to dental procedures and policy, and interpretation of clinical findings. MG contributed to methods, analysis and reporting of findings. RW contributed to positioning of the findings in the international evidence base. ER contributed to ethnicity and oral health evidence. MT contributed to service provider and community health policy considerations. MH contributed to understandings of clinical service delivery in culturally diverse community context. VP contributed to understanding of community service and family context. IG contributed to understanding of cultural influences on families. LM contributed to the study design, statistical analysis and reporting of findings. All authors read and approved the final manuscript.

Funding This project was funded by an Australian Research Council Linkage grant (LP100100223), with cash and in-kind contributions from Linkage partners-Merri Community Health Services, Dental Health Services Victoria, Moreland City Council, Victorian Arabic Social Services, Arabic Welfare and Pakistan Australia Association Melbourne. Additional funding support was also provided by Merri Community Health Services. The authors wish to gratefully acknowledge the Jack Brockhoff Foundation for infrastructure and salary support for Professor EW and Associate Professor LG, and the Australian National Health and Medical Research Council for salary support for LG and La Trobe University for salary support for Associate Professor MG Mandy Truong is a grateful recipient of an Australian Postgraduate Award PhD scholarship. ER is supported by the Murdoch Childrens Research Institute which is supported by the Victorian Government's Operational Infrastructure Support programme. Separate funding grants contributing to the overall research activities were also received from Dental Health Services Victoria and Moreland City Council. The authors wish to thank Colgate-Palmolive Australia for donating the toothbrushes and toothpastes which were included in gift bags for the intervention participants.

Competing interests Consistent with the participatory approach of this study, many of the study authors represented organisations, as listed in their affiliations, that have an interest in or are involved in the delivery of the services described in the intervention.

Ethics approval Ethics approval for this trial was granted by the University of Melbourne Human Research Ethics Committee and the Department of Education and Early Childhood Development Ethics Committee.

Provenance and peer review Not commissioned; externally peer reviewed.

Data sharing statement This paper provides a comprehensive report of the family data collected for the Teeth Tales trial. Papers reporting on the baseline data and the cultural competency organisational review components will be published separately. Ethics approval and participant consent does not include data sharing. Therefore, there is no additional data available.

Open Access This is an Open Access article distributed in accordance with the Creative Commons Attribution Non Commercial (CC BY-NC 4.0) license, which permits others to distribute, remix, adapt, build upon this work noncommercially, and license their derivative works on different terms, provided the original work is properly cited and the use is non-commercial. See: http:// creativecommons.org/licenses/by-nc/4.0/

\section{REFERENCES}

1. Mouradian WE. The face of a child: children's oral health and dental education. J Dent Educ 2001;65:821-31.

2. Al-Yaman F, Bryant M, Sargeant H. Australia's children: their health and wellbeing 2002. Canberra: Australian Institute of Health and Welfare, 2002 
3. Council on Clinical Affairs. Definition of Early Childhood Caries (ECC). American Academy of Pediatric Dentistry, 2008. http://www. aapd.org/assets/1/7/D_ECC.pdf (accessed 28 Nov 2014).

4. Harrison RL, Wong T. An oral health promotion program for an urban minority population of preschool children. Community Dent Oral Epidemiol 2003;31:392-9.

5. Harrison RL, Veronneau J, Leroux B. Effectiveness of maternal counseling in reducing caries in Cree children. $J$ Dent Res 2012;91:1032-7.

6. Slade GD, Bailie RS, Roberts-Thomson K, et al. Effect of health promotion and fluoride varnish on dental caries among Australian Aboriginal children: results from a community-randomized controlled trial. Community Dent Oral Epidemiol 2011;39:29-43.

7. Neumann AS, Lee KJ, Gussy MG, et al. Impact of an oral health intervention on pre-school children $<3$ years of age in a rural setting in Australia. J Paediatr Child Health 2011;47:367-72.

8. Roberts-Thomson KF, Slade GD, Bailie RS, et al. A comprehensive approach to health promotion for the reduction of dental caries in remote Indigenous Australian children: a clustered randomised controlled trial. Int Dent J 2010;60(3 Suppl 2):245-9.

9. Wennhall I, Matsson L, SchrÖDer U, et al. Outcome of an oral health outreach programme for preschool children in a low socioeconomic multicultural area. Int J Paediatr Dent 2008;18:84-90.

10. Plutzer K, Plutzer AJ, Efficacy of an oral health promotion intervention in the prevention of early childhood caries. Community Dent Oral Epidemiol 2008;36:335-46.

11. Vachirarojpisan T, Shinada K, Kawaguchi Y. The process and outcome of a programme for preventing early childhood caries in Thailand. Community Dent Health 2005;22:253-9.

12. Grant JS, Kotch JB, Quinonez RB. Evaluation of knowledge, attitudes, and self-reported behaviors among 3-5 year old school children using an oral health and nutrition intervention. J Clin Pediatr Dent 2010;35:59-64.

13. Pine $\mathrm{CM}$, McGoldrick PM, Burnside $\mathrm{G}$, et al. An intervention programme to establish regular toothbrushing: understanding parents' beliefs and motivating children. Int Dent J 2000; Suppl Creating A Successful:312-23.

14. Marcenes W, Marcenes VE, Muirhead S, et al. Ethnic disparities in the oral health of three- to four-year-old children in East London. Br Dent J 2013;215:E4.

15. Psoter WJ, Pendrys DG, Morse DE, et al. Associations of ethnicity/ race and socioeconomic status with early childhood caries patterns. $J$ Public Health Dent 2006;66:23-9.

16. Riggs $\mathrm{E}$, Gussy M, Gibbs L, et al. Assessing the cultural competence of oral health research conducted with migrant children. Community Dent Oral Epidemiol 2014;42:43-52.

17. McAllan LH. A survey of the gingival health of indo-chinese child refugees. Part II. Aust Dent J 1988;33:91-5.

18. Spencer AJ, Wright FA, Brown LM, et al. Changing caries experience and risk factors in five- and six-year-old Melbourne children. Aust Dent J 1989;34:160-5.

19. Davidson N, Skull S, Calache H, et al. Holes a plenty: oral health status a major issue for newly arrived refugees in Australia. Aust Dent J 2006;51:306-11.

20. Riggs $\mathrm{E}$, Gibbs L, Kilpatrick N, et al. Breaking down the barriers: a qualitative study to understand child oral health in refugee and migrant communities in Australia. Ethnicity and Health 2015;20:241-57.

21. Riggs $\mathrm{E}$, Gussy M, Gibbs L, et al. Hard to reach communities or hard to access services? Migrant mothers' experiences of denta services. Aust Dent J 2014:59:201-7.

22. Fisher-Owens SA, Gansky SA, Platt LJ, et al. Influences on children's oral health: a conceptual model. Pediatrics 2007;120: e510-520.

23. Gibbs L, Waters E, de Silva A, et al. An exploratory trial implementing a community based child oral health promotion intervention for Australian families from refugee and migrant backgrounds: a protocol paper. BMJ Open 2014;4:e004260.
24. Moore L, Gibbs L. Considerations in the design of community-based program evaluations: purpose, resources, complexity, stage. In: Waters E, Swinburn B, Uauy R, Seidell J, eds. Preventing childhood obesity: evidence, policy and practice. UK: Wiley Blackwell, 2010:155-66.

25. Watson MR, Horowitz AM, Garcia I, et al. A community participatory oral health promotion program in an inner-city Latino community. $J$ Public Health Dent 2001;61:34-41.

26. Moore GF, Williams A, Moore L, et al. An exploratory cluster randomised trial of a university halls of residence based social norms marketing campaign to reduce alcohol consumption among 1st year students. Subst Abuse Treat Prev Policy 2013;8:15.

27. Watt RG, Draper AK, Ohly HR, et al. Methodological development of an exploratory randomised controlled trial of an early years' nutrition intervention: the CHERRY programme (Choosing Healthy Eating when Really Young). Matern Child Nutr 2014;10:280-94.

28. MRC Health Services, Public Health Research Board. A framework for development and evaluation of RCTs for complex interventions to improve health. Medical Research Council, 2000.

29. OPHS Office of Minority Health. National standards for culturally and linguistically appropriate services in health care. Washington DC, USA: Department of Health and Human Services, 2001.

30. Cross TL, Bazron BJ, Dennis KW, et al. Towards a culturally competent system of care: vol 1. Washington DC: National Technical Assistance Centre for Children's Mental Health, Georgetown University Child Development Centre, 1989.

31. Blumenthal D, DiClemente R. Community-based health research: issues and methods. New York: Springer Publishing Company, 2004.

32. Gibbs L, Gold L, Kulkens M, et al. Are the potential benefits of a community-based participatory approach to public health research worth the potential costs? Just policy: a journal of Australian social policy 2008(47):54-9.

33. Israel BA, Schulz AJ, Parker EA, et al. Review of community-based research: assessing partnership approaches to improve public health. Annu Rev Public Health 1998;19:173-202.

34. Wallerstein NB, Duran B. Using community-based participatory research to address health disparities. Health Promot Pract 2006;7:312-23.

35. Thompson S, Phillips D. Reaching and engaging hard-to-reach populations with a high proportion of nonassociative members. Qual Health Res 2007:17:1292-303.

36. Kowash MB, Pinfield A, Smith J, et al. Effectiveness on oral health of a long-term health education programme for mothers with young children. Br Dent J 2000;188:201-5.

37. Ismail Al, Sohn W, Tellez M, et al. The International Caries Detection and Assessment System (ICDAS): an integrated system for measuring dental caries. Community Dent Oral Epidemiol 2007;35:170-8.

38. Lobene RR, Mankodi SM, Ciancio SG, et al. Correlations among gingival indices: a methodology study. J Periodontol 1989;60:159-62.

39. Brothwell DJ, Jutai DK, Hawkins RJ. An update of mechanical oral hygiene practices: evidence-based recommendations for disease prevention. J Can Dent Assoc 1998;64:295-306.

40. Marinho VC, Higgins JP, Sheiham A, et al. Fluoride toothpastes for preventing dental caries in children and adolescents. Cochrane Database Syst Rev 2003(1):CD002278.

41. Davies RM, Davies GM, Ellwood RP, et al. Prevention. Part 4: toothbrushing: what advice should be given to patients? Br Dent $J$ 2003;195:135-41.

42. Maserejian NN, Trachtenberg F, Hayes C, et al. Oral health disparities in children of immigrants: dental caries experience at enrollment and during follow-up in the New England Children's Amalgam Trial. J Public Health Dent 2008;68:14-21.

43. World Health Organisation. Ottawa charter for health promotion. Ottawa: Department of Health and Welfare, World Health Organisation, 1986. 